\title{
PARA UMA LITERATURA COMPARADA À BRASILEIRA
}

\section{TOWARDS A BRAZILIAN COMPARATIVE LITERATURE}

\author{
Regina Zilberman ${ }^{1}$
}

\begin{abstract}
RESUMO: José Luís Jobim é autor de Literatura Comparada e Literatura Brasileira: circulações e representações, lançado em 2020. Composto por uma introdução e cinco capítulos, o livro desenvolve, de modo brilhante, a proposta de uma teoria da Literatura Comparada constituída desde as características históricas e temáticas da produção literária brasileira.
\end{abstract}

PALAVRAS-CHAVE: Literatura Comparada; Literatura Brasileira; representação; transculturação.

\begin{abstract}
José Luís Jobim is the author of Comparative Literature and Brazilian Literature: circulations and representations, published in 2020. The book, including an introduction and five chapter, brilliantly develops the proposal for the building of the theory of Comparative Literature founded in the historical and thematic characteristics of Brazilian literary production.
\end{abstract}

KEYWORDS: Comparative Literature; Brazilian Literature; representation; transculturation.

JOBIM, José Luís. Literatura Comparada e Literatura Brasileira: circulações e representações. Boa Vista; Rio de Janeiro: Editora UFRR; Edições Makunaima, 2020. 161 p. (e-book) http://edicoesmakunaima.com.br/images/livros/literatura-comparada-e-literatura-brasileira.pdf

José Luís Jobim, em Literatura Comparada e Literatura Brasileira: circulações e representações (2000), paga, desde um título, um tributo a Antonio Candido que, em conferência durante o primeiro congresso da Abralic, afirmou com convicção: "estudar literatura brasileira é estudar literatura comparada". A adoção da assertiva do provavelmente principal historiador e pensador da literatura nacional tem suas consequências, que são assumidas por José Luís Jobim:

a) Significa primeiramente que a literatura brasileira, enquanto área de conhecimento, não é um campo isolado, e só pode ser entendida desde suas relações com o conjunto de suas

\footnotetext{
${ }^{1}$ Universidade Federal do Rio Grande do Sul - UFRGS, Instituto de Letras, Programa de Pós-Graduação em Letras, Porto Alegre, Rio Grande do Sul, Brasil; CNPq; https://orcid.org/0000-0002-0834-214X ;

regina.zilberman@gmail.com
} 
interlocuções com as demais tradições literárias, tanto as que a precedem cronologicamente, como as que a simultaneamente acompanham.

Em outras palavras, não há lugar para o isolacionismo (a síndrome de "Agar no Deserto", a que se refere Roger Bastide [1975] nos idos de 1970) quando se fala em literatura brasileira. É o que, enquanto atitude, de uma parte, se comprova no âmbito da docência da literatura brasileira na escola e na universidade - afinal, examinam-se autores e obras em função de seu enquadramento e diálogo com poéticas nascidas fora do país; mas que, de outra parte, se coloca na contramão da tendência a buscar a singularidade ou a identidade da produção artística nacional.

b) Em segundo lugar, a adoção da frase de Candido como princípio motor da obra significa que talvez seja possível construir uma teoria da literatura comparada a partir da literatura produzida e em circulação no Brasil.

Esse é, certamente, o aspecto mais importante do livro assinado por José Luís Jobim, formado por uma introdução e mais cinco capítulos, todos de natureza ensaística. Ele supõe que não se trata apenas de praticar a Literatura Comparada enquanto metodologia ou absorver alguns de seus pressupostos, mas de refletir sobre a natureza daquela ciência desde uma perspectiva muitas vezes avaliada como subalterna ou secundária, já que dependente dos influxos externos a ela. Não por outra razão a noção de influência esteve presente por muito tempo no universo da Literatura Comparada, conforme um vetor que se orienta do centro (nações europeias hegemônicas) para a periferia.

Trata-se, pois, de encarar um desafio e de propor uma tarefa, que começa pela definição dos termos como será exercida. Na introdução, que não tem um título como os demais segmentos, mas que efetivamente é um capítulo independente, Jobim contesta dois conceitos que embasam a visão comparatista quando essa se defronta com produtos de países como o nosso, cuja tradição literária construiu-se, à primeira vista, à sombra de outras mais poderosas: os de falta e de aclimatação. Em ambos, identifica-se a perspectiva eurocêntrica e colonialista, já que a produção literária é entendida, de uma parte, pelo que não tem - a falta -, de outra, pelo que importou, para preencher as lacunas - a aclimatação.

Ambos os conceitos diminuem o objeto com que lidam, pois ele se define pelo negativo. As literaturas hegemônicas, a partir das quais se conhece a literatura brasileira, oferecem um espelho no qual a literatura nacional - esse "galho secundário da portuguesa, por sua vez arbusto de segunda ordem no jardim das Musas", como primorosamente descreve Antônio Candido (2014, p. 11) em A formação da literatura brasileira -, não se reconhece, buscando compensar a ausência pela imitação. A essa concepção, José Luís Jobim oferece outra. Que, de certo modo, seguindo o caminho sugerido por Candido no livro mencionado, não se caracteriza pela negação da imagem deformada, exaltando conquistas imaginárias, mas pela identificação dos processos de criação próprios às regiões marcadas pelo colonialismo e pela apropriação de culturas distintas. Assim, à teoria da falta, Jobim contrapõe a noção de diferença, e à de aclimatação, a de transculturação. Do reconhecimento desses processos provém o procedimento metodológico, calcado no entendimento do modo como se dá a circulação das poéticas em dados tempo e espaço. Embora Jobim não recorre à terminologia proposta por M. Bakhtin, pode-se distinguir em sua metodologia como operam, em uma literatura, o dialogismo e o hibridismo, fenômenos próprios aos processos de criação e circulação de bens artísticos caracterizados por sua índole democrática e igualitária.

O foco teórico proposto determina uma metodologia que não pode se limitar a "coletar referências e menções explícitas e implícitas a autores e obras europeias em um escritor brasileiro", como escreve Jobim na p. 37, exercício que se intensificou desde a consolidação de conceitos pós-estruturalistas, como o de intertextualidade. Não é nesse ponto que se verifica o exercício comparatista; ele ocorre quando se verifica "que papel têm essas referências e 
menções", o que incide em identificação do procedimento criativo, a interpretação e o dialogismo.

Não se esgotam nesse estágio as tarefas de uma Literatura Comparada nascida da contribuição da Literatura Brasileira. É igualmente incumbência sua identificar como se dá a circulação dos bens culturais, vale dizer, como acontecem a transculturação e a transferência. O exame de "O lapso", de Machado de Assis, ajuda a entender o raciocínio: na história do indivíduo que esquece de pagar as dívidas contraídas, Machado introduz, por via indireta, o tema do livro As doenças da memória, de Théodule-Armand Ribot (encontrável em sua biblioteca, conservada pela Academia Brasileira de Letras), para evidenciar, por meio do humor e da paródia, os equívocos de um certo tipo de ciência, na moda à época da publicação do conto. Assim, o ficcionista carioca incorpora um saber de seu tempo para, diante dele, tomar distância crítica, desconstruindo seus achados. Ao mesmo tempo, Machado posiciona-se de modo independente diante do cientificismo corrente, que, mesmo nos centros hegemônicos da cultura, adonou-se do fazer literário, subordinando-o a seus intentos, de que é exemplo a poética naturalista, proclamada por Émile Zola.

Associados aos pressupostos teóricos, três outros pontos são matéria de exame. Dizem respeito à trajetória da literatura brasileira, mas colaboram para a estruturação de uma prática da Literatura Comparada desde o lugar histórico e cultural ocupado pelo pesquisador. São eles: a representação da alteridade; as escolhas linguísticas; a apropriação de poéticas estrangeiras.

A questão da representação esteve presente desde as as primeiras histórias das literaturas em língua portuguesa. Fosse a da natureza, da sociedade ou da cultura popular, constituiu responsabilidade atribuída aos artistas dar a conhecer o país aos cidadãos que residiam nele. Formulada inicialmente por historiadores estrangeiros da literatura, como Ferdinand Denis e Almeida Garrett, a tarefa prescrita manteve-se viva por muito tempo, a ponto de, em 1873, Machado de Assis discutir sua validade em "Notícia da atual literatura brasileira - Instinto da nacionalidade".

Válida ou não, a longevidade da questão sugere sua pertinência, sendo mais importante, para uma literatura comparada fundada na literatura brasileira, constatar sua existência do que debater as eventuais respostas que se podem dar a ela. Até porque ela pode envolver dilemas não facilmente solucionáveis, como o que José Luís Jobim relembra, apoiado na pesquisa de Wail Hassan, sobre a representação da cultura árabe ou oriental em uma literatura do Ocidente. O exótico, neste caso, é condenável, como acusou Edward Saïd? Ou é o caso de entendê-lo de modo dialético, como contraposição entre duas normalidades, as de dois mundos - o oriental e o ocidental - em confronto?

Eis o que cabe à Literatura Comparada pesquisar, se calcada em uma tradição literária originária de países formados pelo regime colonial e sujeitos às interferências de culturas distintas.

A mescla cultural, por sua vez, reproduz-se em outra instância - a de ordem linguística, pois a história de uma língua nacional em um país como o Brasil não é idêntica à dos país europeus, como Portugal ou França, seus principais espelhos. Tanto na Europa como na América, as línguas nacionais se edificaram a partir da supremacia de um grupo étnico ou camada sócioeconômica sobre outra. Porém, na América, o processo foi acelerado em decorrência não apenas do extermínio ou da dominação dos povos nativos, como, depois de imposta a língua oficial, da interferência de outros contingentes de imigrantes, provenientes dos distintos continentes do planeta, provocando sucessivas mutações. A língua portuguesa praticada no Brasil tornou-se, assim, muito mais permeável a intervenção de outros idiomas, seja o francês, discutido no capítulo "Brasil ou França? Dilemas do modernismo brasileiro, nas cartas dos anos 20", como, atualmente, o inglês. Contudo, essas incorporações são atravessadas por adaptações, como traduções incorretas (save significando salvar, na informática), aportuguesamentos (print e seus 
derivados, para as ações relacionadas à impressão), ou meros confiscos (denominação escape para uma das peças do teclado ou o hoje praticadíssimo delivery).

Tais apropriações linguísticas conferem maleabilidade à língua do país, e sua natureza é matéria de investigação por quem a utiliza no terreno literário, como propõe Jobim, ao elencar as tarefas da Literatura Comparada construída desde a Literatura Brasileira.

Como se posicionar diante as poéticas estrangeiras e de seus símbolos? Ao examinar a circulação das figuras emblemáticas de Caliban e Ariel, Jobim pode verificar como os significados variam ao migrar de um continente a outro. Caliban, o canibal, pode ser o antropófogo desenhado por Oswald de Andrade no Manifesto de 1928, invertendo os sinais que descrevem aquela personalidade como bárbara, violenta, indomada e merecedora de eliminação. Com isso, sem deixar de ser quem é, Caliban pode ser um herói para os latinoamericanos ou africanos escravizados, mas sedentos de liberdade; mas pode ser também um retrato de sua baixa-estima diante dos poderes hegemônicos de Próspero, cujo progresso está inscrito no próprio nome.

Eis a dialética que rege a criação literária em países dependentes como o nosso. Mas que suscitam uma Literatura Comparada que segue regras próprias, como sugere José Luís Jobim em seu livro, de leitura e discussão obrigatórias.

\section{REFERÊNCIAS:}

BASTIDE, Roger. Iphigenie en Tauride ou Agar dans le desert? (essai d'analyse critique des mécanismes de penétration culturelle au Brésil). In: Idéologies, littérature et societé en Amérique Latine. Bruxelas: Editions de l'Université de Bruxelles, 1975.

CANDIDO, Antonio. Formação da literatura brasileira. Momentos decisivos. Rio de Janeiro: Ouro sobre Azul, 2014.

JOBIM, José Luís. Literatura Comparada e Literatura Brasileira: circulações e representações. Rio de Janeiro: Editora UFRR; Edições Makunaima, 2020. 161 p. (e-book).

Regina Zilberman é Doutora em Romanística pela Universidade de Heidelberg e pesquisadora do CNPq, com pós-doutorado no University College e na Brown University, e professora associada na UFRGS. É autora de Brás Cubas autor Machado de Assis leitor e de Estética da recepção e história da literatura, entre outras publicações. Coordena o projeto Discurso da épica nas culturas lusófonas do século XIX-Probral Capes/DAAD 2018-2021.

Submetido em $15 / 06 / 2020$

Aprovado em 15/07/2020 